\section{Antoine Breguet's Appropriations}

ON looking through the recent brochure on the Gramme machine by M. Antoine Breguet, I observe that the author has appropriated, without acknowledgment, a large number of the beautifully executed Magnetic Figures which Prof. Silvanus Thompson has long since published, both in your columns (November 28, 1878) and elsewhere. So far as the eye can judge, M. Breguet's illustrations are printed from clichés of the very blocks used in Prof. Thompson's papers. If-as I understand was the case-M. Breguet's attention was called to the omission when he employed a similar illustration in a paper of his, which appeared some little time aro in the Ann. de Chimie et de Physique, the present oversight ought not to pass without some protest - the more emphatic as some of Prof. Thompson's figures are entirely new and of much theoretical and practical importance.

Royal College of Science, February 4

\section{On the Clenching of the Hands from Emotional and other Causes in the Two Sexes}

I SHould like to invite the attention of readers of this paper to the above subject when they have the opportunity of making personal observations, believing myself to have noticed a curious distinction. The number of my own cases, though sufficient to warrant me in broaching the topic, is not large enough to enable me to form definite conclusions. Whether the clenching of the hand be the result of mental emotion, of hysteria, or other nervous convulsion, of acute poisoning or of tetanus, women always seem to lay the thumb across the palm and fold the fingers over it, frequently wounding the skin of the ball of the thumb by the pressure of the index and middle finger-nails; while men invariably flex the fingers acutely first, now and then digging all four nails into the palm, and turn the thumb outside, across the back of the middle phalanges. $\mathrm{Ab}$, ut four years ago I witnes ed a case of idiopathic tetanus in a black woman in Barbad is; the disease had reached that advanced stage where the muscles of the extremities bevin to be affected during the paroxysms, and it was interesting to observe, before actual clenching ensued, that the thumb first began to twitch inwardly, while the fingers were motionless. Possibly, this may be the unconscions result of habits acquired during life; I have had no opportunity of noting the phenomenon in children. Perhaps those who read this in the tropics, where there is usually plenty of tetanus, hydrophobia, and other convulsive maladies, will kindly communicate their experience. ARTHUR STRADLING

\section{Parhelia in the Mediterranean-The Weather in Switzerland}

THE parhelia of January 27 , which $\mathrm{Mr}$. Ch. H. Allen in Mentone describes, has also been observed at several places in Switzerland: for instance, at Glaris and at Basle. The phenomenon has here been more completely developed; the sun appeared surrounded by two lightly-coloured halos of $46^{\circ}$ and $92^{\circ}$ in diameter. Owing to the sun's low altitude, little more than the semi-circumference of them was visible. Each of these halos had on its summit a tangent arc, turning its convexity towards the sun, the arc on the greater circle shming, as usual, in brilliant colours. On the inner halo, in the same altitude with the sun, two mock suns of a reddısh tint were seen; a third appeared at the summit of the same circle at the junction with the tangent arc. All circles turned their red side to the sun. That part of the sky was covered with taint cirrus. The spectacle lasted from 2 to 4 p.m. In the evening of the 27 th and also of the 29 th the common halo of $46^{\circ}$ diameter was seen round the moon. During the night of the 3 oth to the 3 Ist some snow fell (melted $2.8 \mathrm{~mm}$. in the rain-gauge), the first in this year.

On January 29, at $3.2 \mathrm{p.m}$, a brilliant meteor with a bluish trail was observed falling in a south-easterly direction; it vanished about $15^{\circ}$ above the horizon. The same meteor was. noticed at Scanfs in the Engadine, where a heavy detonation was heard.

The Basle section of the S.A.C. ascended Mount Pilate, near Lucerne, on January 28 . The extreme transparency of the air afforded a view more splendid than is to be seen in summer. The minutest details of the Jura, and of the Black Forest and the hills of the Höhgan near the Lake of Constance, could be perccived; only the Vosges Mountains were a little dimmed.
An ocean-like fog spread over the low parts of the country at a level of about $650 \mathrm{~m}$. above sea. On the summit of Mount Pilate the thermometer marked $-4^{\circ} \mathrm{C} .\left(25^{\circ} \mathrm{F}\right.$.) during the night, and $+\mathrm{I}^{\circ} \mathrm{C} .\left(34^{\circ} \mathrm{F}\right.$.) before sunrise. Over the surface of the Lake of Lucerne the air temperature was, at noon of the 29th, $-2^{\circ} \cdot 5 \mathrm{C} .\left(27^{\circ} 5 \mathrm{~F}\right.$. $)$; above the fog an hour before, $+4^{\circ} \mathrm{C}$. $\left(39^{\circ} \mathrm{F}.\right)$.

Basle, February II

ALBERT RIGGENBACH

\section{On the Climate of North Northumberland as Regards} its Fitness for Astronomical Observations

I HAVE looked again at my observations (p. 3I7), and can assure Mr. Joseph Lingwood of their entire accuracy. For astronomical purposes the sky is "completely overcast" when not a star is visible. As the observations in question referred to the year I $88 \mathrm{r}$, I do not see what the "weather since taken" has to do with the question, unless it be contended that the weather in Jannary, I88r, was precisely similar to the weather in January of the present year. As a general rule the observations would refer to a later hour than $6 \mathrm{p} . \mathrm{m}$.

S. Paul's Vicarage, Alnwick, February I 3

JeVon J. Muschamp Perry

\section{Jago's "Inorganic Chemistry"}

THE kind tone of the first part of the notice, in your issue of December I5 (vol. xxv. p. I50), of my work on Inorganic Chemistry leads me, with your permission, to reply to some questions asked by the reviewer in the latter portion of his remarks. He first inquires "Why should he (the student) begin his chemical career by learning that 'combining weight' is synonymous with 'atomic weight'?" To this I answer, Because in our best standard works on chemistry these terms are applied indifferently to the same series of numbers; and further that the combining weight, a number deduced from experiment, is according to the atomic theory the relative weight of the atom of that particular element. To the query "Why should he draw from the statement of Avogadro's law the erroneous conclusion that the molecules of all gases are of the same size?" I reply by pointing out that Frankland states that the bulk of any elementary molecule, in the gaseous condition, is the same as that of hydrogen; and that Roscoe, Miller, and Tilden affirm that all gaseous molecules occupy the same volume. The phrase "are of the same size" is simply intended to convey, the same meaning as the term "occupy the same volume." I have not deemed it necessary in such a work as that under review to point out that the volume occupied by a molecule consists in part of intermolecular space; neither do the works of the chemists quoted when explaining the same law.

My own experience of teaching ci.emistry has convinced me that a knowledge of the "atomicity" of the most important elements is a vast help to even young students, as thereby they learn to write formulæ and equations not merely from memory, but in accordance with certain definite rules. The value of graphic formulæ is considerable, and with sufficient space at my disposal I should be quite prepared to demonstrate that the formula referred to of nitruus oxide does afford a reasonable hypothesis of the molecular constitution of that compound. Although I hold these opinions I have however carefully pointed out (p. I 106 ) that the so called laws of atomicity are not always obeyed, and have dealt at some length with the notable exception, nitric oxide $\mathrm{NO}$.

I regret to thus trespass on your valuable space, but in justice to myself and the work thus reviewed I ask you to kindly insert this letter.

School of Science and Art, Brighton

["Combining weight" is not synonymous with "atomic weight," e.g. $4^{\circ} 6$ parts by weight of nitrogen combine with I part by weight of hydrogen, but the atom of nitrogen is 14 times heavier than the atom of hydrogen; 8 parts by weight of oxygen combine with I part by weight of hydrogen, but the atomic weight of oxygen is 16 , that of hydrogen being $\mathbf{1}$. In some cases, e.s: chlorine, the combining and atomic weights are represented by the same number. I admit that the terms in question are applied to the same series of numbers, in many standard books on chemistry, but I maintain that they are applied erroneously.

I cannot admit that because "equal volumes of gases contain equal numbers of molecules" therefore "all gaseous molecules 